\title{
Screening of free carnitine and acyl-carnitine status in patients with Familial Mediterranean Fever
}

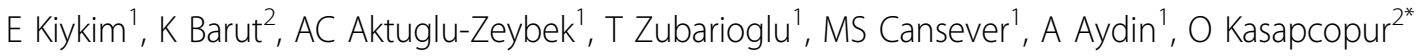 \\ From 8th International Congress of Familial Mediterranean Fever and Systemic Autoinflammatory Diseases \\ Dresden, Germany. 30 September - 3 October 2015
}

\section{Introduction}

Familial Mediterranean fever (FMF) is an autosomal recessive disease characterized by recurring self-limited fever, abdominal pain and chest pain caused by serositis. FMF mainly affects Middle-East populations with a high prevalence in Sephardic Jews, Turkish, Arabs and Armenians. Carnitine is an important molecule in cellular energy metabolism. Secondary carnitine deficiency can be detected in chronic diseases by either renal loss or increased needs.

\section{Objectives}

Our hypothesis was that FMF patients would have lower free carnitine levels than their healthy age and gender matched controls due to increased need of carnitine because of recurrent auto-inflammation. The present study was conducted to determine the patterns of free carnitine and acyl-carnitine esters in FMF patients.

\section{Methods}

This is a cross-sectional study of 205 FMF patients who were attending the outpatient Pediatric Rheumatology clinic of Cerrahpasa Medical Faculty Children's Hospital. The patients were selected by random sampling and FMF diagnosis was confirmed by a pediatric rheumatologist according to Yalcınkaya criteria. 50 healthy subsects were enrolled to the present study. A fasting died blood sample was taken for studying free carnitine and acyl-carnitine esters with tandem mass spectrometry from children in both groups.

\section{Results}

Acyl-carnitine analyses in spot dried blood samples with ESI-MS/MS were performed in all patients and control

\footnotetext{
${ }^{2}$ Istanbul University, Cerrahpasa Medical Faculty, Pediatric Rheumatology, Istanbul, Turkey

Full list of author information is available at the end of the article
}

group. Screening of acyl-carnitine profile revealed free carnitine, $\mathrm{C} 16-\mathrm{OH}$ and $\mathrm{C} 18: 2$ carnitine levels were higher $(\mathrm{p}<0,0001, \mathrm{p}<0,0001$ and $\mathrm{p}-0,003$ respectively), while $\mathrm{C4}$ $\mathrm{OH}$ and $\mathrm{C} 4 \mathrm{DC}$ carnitine levels were lower $(\mathrm{p}<0,0001)$ in FMF patients than the control group.

\section{Conclusions}

In the present study we were not able to define secondary carnitine deficiency in FMF patients, therefore usage of carnitine in all patients with FMF is not recommended.

\footnotetext{
Authors' details

${ }^{1}$ Istanbul University, Cerrahpasa Medical Faculty, Pediatric Metabolic Diseases, Istanbul, Turkey. ${ }^{2}$ Istanbul University, Cerrahpasa Medical Faculty, Pediatric
} Rheumatology, Istanbul, Turkey.

Published: 28 September 2015

doi:10.1186/1546-0096-13-S1-P77

Cite this article as: Kiykim et al: Screening of free carnitine and acylcarnitine status in patients with Familial Mediterranean Fever. Pediatric Rheumatology 2015 13(Suppl 1):P77.

Submit your next manuscript to BioMed Central and take full advantage of:

- Convenient online submission

- Thorough peer review

- No space constraints or color figure charges

- Immediate publication on acceptance

- Inclusion in PubMed, CAS, Scopus and Google Scholar

- Research which is freely available for redistribution

Submit your manuscript at www.biomedcentral.com/submit

\section{() Biomed Central}

